\title{
ENCONTRO NACIONAL ACADÊMICO DE SECRETARIADO EXECUTIVO - ENASEC: UM ESTUDO BIBLIOMÉTRICO
}

\section{ACADEMIC NATIONAL MEETING OF THE EXECUTIVE SECRETARIAT - ENASEC: A BIBLIOMETRIC STUDY}

\section{Caroline Monteiro}

Mestre em Administração pela Universidade Estadual do Centro-Oeste - UNICENTRO, Paraná (Brasil). Professora pela Universidade Estadual do Centro Oeste - UNICENTRO, Paraná (Brasil).

E-mail: kcarolmonteiro@gmail.com

\section{Katiane Crotti}

Mestranda em Administração pela Universidade Estadual do Centro-Oeste - UNICENTRO, Paraná (Brasil). Professora pela Universidade Estadual do Centro Oeste - UNICENTRO, Paraná (Brasil).

E-mail: katycrotti@hotmail.com

\section{Carla Santos}

Bacharel em Secretariado Executivo pela Universidade Estadual do Centro-Oeste - UNICENTRO, Paraná (Brasil). Cursando especialização em Docência no Ensino Superior pela Centro Universitário de Maringá -UNICESUMAR, Paraná (Brasil). E-mail: carlinha sts@ hotmail.com 


\section{ENCONTRO NACIONAL ACADÊMICO DE SECRETARIADO EXECUTIVO - ENASEC: UM ESTUDO BIBLIOMÉTRICO}

\section{RESUMO}

Considera-se o Encontro Nacional Acadêmico de Secretariado Executivo - Enasec um evento bastante relevante ao Secretariado Executivo por permitir a discussão de temas da área secretarial, a partir do viés acadêmico promovido pela Associação Brasileira de Pesquisa em Secretariado (ABPSEC). Por isso, este estudo, de abordagem quantitativa, possui como objetivo geral: analisar bibliometricamente a produção científica dos autores nos anais do Enasec, categorizando-as por grupos de trabalho. E como objetivos específicos: identificar as áreas de concentração das produções científicas; verificar a evolução do número de publicações por grupo de trabalho; levantar o número de ocorrências dos termos relacionados à área secretarial; e levantar a reincidência de publicações por instituição nas produções científicas, dos trabalhos completos, nos anais do Enasec. Nesse contexto, tem como questionamento: quais as possibilidades de linha de pesquisa em secretariado executivo, com base nas produções científicas publicadas nos anais do Enasec nas quatro edições do evento? Concluiu-se que não é possível inferir sobre as linhas de pesquisas devido ao pequeno número de publicações existentes no evento. Ainda, verifica-se que, para que a área de secretariado se consolide como ciência, produções precisam ser estimuladas.

Palavras-chave: Secretariado Executivo. Enasec. Estudo bibliométrico. 


\title{
ACADEMIC NATIONAL MEETING OF THE EXECUTIVE SECRETARIAT - ENASEC: A BIBLIOMETRIC STUDY
}

\begin{abstract}
It is considered the National Meeting Academic Executive Secretariat - Enasec a very important event to the Executive Secretariat for allowing the discussion of issues of secretarial area, from the academic bias promoted by the Brazilian Association of Research Secretariat (ABPSEC). Therefore, this study, a quantitative approach, has as main objective to analyze the scientific production in a bibliometric way of authors in the annals Enasec, categorizing them by working groups. And the following objectives: identify areas of concentration of scientific production; check the evolution of the number of publications by the working group; raise the number of appearances of suits related to the secretarial area; and raise the recurrence of publications per institution in scientific production, the complete works in Enasec the proceedings. In this context, it has the question: what line of research possibilities Executive Secretariat, based on scientific production published in the annals of Enasec in the four editions of the event? It was concluded that it is not possible to infer about the lines of research due to the small number of publications in the event. Still, it is clear that for the secretariat area is consolidated as a science, productions need to be stimulated.
\end{abstract}

Keywords: Executive Secretariat. Enasec. Bibliometric study. 


\section{INTRODUÇÃO}

A profissão de Secretariado Executivo passa, constantemente, por evoluções significativas que contribuem para o crescimento e fortalecimento da área. De acordo com Nonato Júnior (2009), os mecanismos técnicos, táticos e estratégicos do secretariado executivo mudaram consideravelmente nas últimas três décadas, possibilitando aproximar-se de novas tecnologias e atender novas demandas do mercado.

No campo da educação, a profissão também teve diversas conquistas a partir da instauração e disseminação dos cursos superiores pelas universidades no Brasil, abrindo o caminho para a pesquisa científica no secretariado (Nonato Júnior, 2009). No entanto, verifica-se que "a pesquisa científica é incipiente entre os profissionais da área" (Bíscoli \& Bilert, 2013, p. 12). Durante (2012) corrobora as autoras e ressalta que talvez devido à formação acadêmica no secretariado ainda ser recente, não se instaurou a cultura da pesquisa científica, por esta razão ainda possuem poucas literaturas disponíveis.

A pesquisa no secretariado encontra-se em fase inicial, portanto, existe um percurso a ser transcorrido, a fim de solidificar a área em termos acadêmicos e produzir avanços de conhecimentos científicos (Iizuka \& Almeida, 2014). Com isso, identifica-se a necessidade de mais produções científicas na área para que se consiga vincular o secretariado como um campo de conhecimento científico (Nonato Júnior, 2009; Maçaneiro, 2012; Bíscoli \& Bilert 2013). Para tanto, Maçaneiro (2012, p. 78) ressalta que "são necessárias reflexões e discussões inerentes à construção da identidade científica na área de secretariado executivo, para que possamos crescer e se firmar enquanto ciência".

Bíscoli e Bilert (2013), dentre outros autores, destacam alguns fatores que dificultam a evolução da pesquisa científica em secretariado. Um deles refere-se à ausência de cursos de mestrados e doutorados na área, outro fator é a existência de poucas revistas científicas para divulgação de trabalhos científicos inerentes ao secretariado, e também da pouca existência de eventos científicos para que se possam divulgar tais pesquisas.

Segundo Bíscoli (2012), o Enasec conquistou o reconhecimento dos docentes, pesquisadores e profissionais da área como uma iniciativa importante ao desenvolvimento da pesquisa em secretariado executivo, devido à formatação dos trabalhos e pela participação nacional de pesquisadores nas discussões para estruturar a área e conquistar os avanços na pesquisa. 
O evento conta com quatro edições realizadas nos anos de 2010, 2011, 2013 e 2015. Considerando os trabalhos completos publicados na primeira edição houve 14 pesquisas aprovadas. Já em 2011, houve um aumento significativo, o número total foi de 40 trabalhos, e no ano de 2013 a quantidade pode ser considerada equitativa à de 2011: foram 39 os trabalhos completos. Todavia em 2015 houve uma redução no número de publicações totalizando 28 trabalhos.

Deste modo, o Enasec configura-se como um evento que possibilita a divulgação das pesquisas no secretariado por permitir a discussão dos diversos temas que compõem a área do Secretariado Executivo. Nesse contexto, esta pesquisa possui como problemática norteadora, o seguinte questionamento: Quais as possibilidades de linha de pesquisa em secretariado executivo, com base nas produções científicas publicadas nos anais do Enasec nas quatro edições do evento?

Para tanto, tem-se como objetivo geral analisar bibliometricamente a produção científica dos autores nos anais do Enasec, categorizando-as por grupos de trabalho. Para tanto, utilizaram-se oito categorias tendo como base os grupos de trabalhos definidos pela ABPSEC.

Assim, para alcançar o propósito central do artigo estabeleceram-se os seguintes objetivos específicos: a) identificar as áreas de concentração das produções científicas nas edições do evento; b) verificar a evolução do número de publicações por grupo de trabalho do evento; c) levantar o número de ocorrências dos termos relacionados à área secretarial e identificar a reincidência dos autores mais citados nos trabalhos analisados; d) levantar a reincidência de publicações por instituição nas produções científicas, dos trabalhos completos, nos anais do Enasec.

Para tanto, o número de trabalhos completos por evento totaliza 121. Na primeira edição, o total foi de 14 trabalhos completos; na segunda edição foram 40. Já na terceira edição foram 39 e na quarta edição os trabalhos completos totalizaram 28.

Com isso, o desenvolvimento desta pesquisa justifica-se por demonstrar a importância do evento como meio de divulgação e publicação das pesquisas realizadas, gerando a oportunidade de debates teórico-críticos, que oportunizem reflexão e interação, estimulando a produção científica na área secretarial possibilitando, dessa forma, aliar a teoria à prática. A pesquisa também se justifica por servir de estímulo aos pesquisadores, profissionais e docentes para continuarem realizando pesquisas científicas, bem como demonstrar sobre as 
possibilidades de linha de pesquisa em secretariado executivo, além de traçar um perfil geral sobre a produção científica do secretariado.

Este artigo compõe-se de cinco partes: a primeira delas refere-se a esta introdução; a segunda apresenta o referencial teórico acerca da temática levantada; a seguinte contempla os procedimentos metodológicos utilizados nesta pesquisa; e na sequência, os dados são tratados e analisados; e por fim, as principais conclusões e contribuições do estudo são expostas juntamente com as sugestões de pesquisas futuras.

\section{REFERENCIAL TEÓRICO}

\section{A necessidade de evolução do campo secretarial por meio da pesquisa}

O cenário de mudanças e avanços do mercado exigiu que o profissional de Secretariado Executivo se adaptasse à nova realidade organizacional, o que demandou novos conhecimentos, aprendizados e produções científicas que pudessem ser fonte de consulta e aprimoramento (Cordeiro \& Fávero, 2011).

Para Reis (2011) as evoluções do perfil dos profissionais secretariais, provindas da globalização, demandaram que as instituições de ensino superior voltassem sua atuação para a formação dos acadêmicos de acordo com as necessidades do mercado, visto que, o curso de nível superior de secretariado possibilita uma formação e preparação mais completa, sólida e interdisciplinar dos profissionais para o mercado de trabalho (Durante et al., 2011).

Bíscoli e Cielo (2004) afirmam a evolução do perfil desse profissional instiga mudanças curriculares a fim de transformar os cursos superiores em formadores de profissionais que, além do cumprimento das rotinas secretariais, sejam capazes de compreender a organização e suas atitudes.

Nesse contexto, destaca-se o estudo realizado por Cielo et al. (2014) que teve por objetivo compreender o cenário dos cursos de graduação em Secretariado Executivo no país. As autoras mapearam a oferta dos cursos de graduação nas distintas regiões do país. Os principais resultados apontam que há um significativo processo de retração na oferta de cursos de bacharelado na área desde 2006: da totalidade dos formalmente criados no país, apenas $52 \%$ estão em pleno funcionamento. Diante disso, não se pode afirmar que a profissão de secretariado vem desaparecendo, mas sim que outras modalidades de formação na área estão em processo de expansão, por exemplo dos cursos de tecnologia. Para tanto, a compreensão 
do panorama da formação do profissional é fundamental para que conjeturas futuras possam ser delineadas.

Verifica-se, assim, que além da prática, a área precisa se fortalecer com pesquisas científicas. Nesse sentido, Françoso e Jonas (2011, p. 5) explanam que:

É importante lembrar que o curso não pode basear-se exclusivamente na aplicação prática, é imprescindível a complementação do conhecimento gerado pelas pesquisas científicas, que são componentes intelectuais necessários à construção do mundo profissional e acadêmico.

Assim, para haver prática é necessário conhecer e desenvolver o campo teórico que embasará toda a aplicação prática das atividades secretariais. Por essa razão, torna-se relevante despertar nos acadêmicos o interesse pela pesquisa científica por meio da participação de projetos, o que auxiliará os futuros profissionais a compreender melhor o campo em que atuarão. Além disso, torna-se importante o envolvimento dos acadêmicos em grupos de estudos para que a produção científica na área consiga alavancar (Françoso \& Jonas, 2011).

Entretanto, para atender a demanda de pesquisas aplicadas ao secretariado, os cursos superiores buscam responder aos diversos questionamentos que emergem na profissão, como também procuram avançar os estudos científicos com o intuito de descobrir uma identidade ao curso de Secretariado Executivo (Cordeiro \& Fávero, 2011).

Nonato Júnior (2009, p. 130) propõe uma epistemologia do secretariado, pois acredita que "uma área que não possui seus próprios conceitos de ordem filosófica e científica ficará sempre atrofiada à condição de técnica ou, no máximo, de resenha sobre o conhecimento das outras ciências". Dessa forma, pode-se inferir que a epistemologia tem como finalidade investigar o Secretariado como área do conhecimento, considerando suas características, potencialidades e suas relações históricas e teóricas. Sob tal perspectiva, Cordeiro e Fávero (2011, p. 5) acrescentam que “[...] por mais esforço que vários profissionais façam dentro da academia, ainda falta alavancar a profissão para o pensamento científico, ou seja, que a área desenvolva a sua própria vertente filosófica". No entanto, a pesquisa científica em secretariado executivo tem se demonstrado persistente na busca pela construção da identidade secretarial (Maçaneiro, 2012), e está aberta a dialogar com outras áreas do conhecimento a fim de se tornar uma importante área do saber (Cordeiro \& Fávero, 2011). 


\section{Importância da pesquisa científica para o Secretariado}

A partir dos estudos levantados, observou-se que somente será possível o Secretariado Executivo evoluir como ciência e ter seu campo de conhecimento próprio, se a pesquisa conquistar credibilidade, pois "a pesquisa é o que fundamenta a ciência" (Cordeiro \& Fávero, 2011, p. 3). Para Bíscoli (2012, p. 38) “é perceptível a necessidade de evolução teórica e conceitual na área do secretariado executivo, o que poderá se concretizar a partir da pesquisa científica bem estruturada".

Para a produção do conhecimento científico são necessários recursos metodológicos, levantamento da literatura sobre o tema e processos investigativos que compõem a pesquisa (Fávero, 2012; Arruda, 2013). Além disso, Arruda (2013, p. 8) ressalta que:

\footnotetext{
Cabe ainda, aos profissionais do Secretariado Executivo em geral e, mais especificamente, àqueles inseridos no contexto acadêmico, não apenas o domínio dos mais variados métodos e técnicas de pesquisa científica disponíveis, enquanto ferramentas de trabalho, como também o desenvolvimento de uma consciência epistemológica capaz de fortalecer seu papel de produtores do conhecimento.
}

As autoras Bíscoli e Bilert (2013) também destacam que há a necessidade de se estruturar a pesquisa em Secretariado Executivo, mas existem alguns fatores que dificultam essa consolidação da pesquisa. Hoje, ainda não existem linhas de pesquisa reconhecidas; isso se dá devido à "falta de esclarecimento junto aos órgãos competentes e mesmo entre a categoria de docentes e pesquisadores com uma visão clara das perspectivas teóricas possíveis para área do secretariado" (Bíscoli, 2012, p. 41).

Com isso, a ausência de linhas de pesquisa reconhecidas pela Coordenação de Aperfeiçoamento de Pessoal de Nível Superior - Capes dificulta o estabelecimento de cursos de mestrados e doutorados na área, o que pode ser considerado como barreira, pois a formação dos docentes em cursos de pós-graduação traz credibilidade às pesquisas desenvolvidas. Considera-se que as revistas científicas são os principais meios para levar à sociedade o conhecimento construído a partir das pesquisas; outro fator levantado trata da existência de poucas revistas científicas com Qualis reconhecido pela Capes para a divulgação das pesquisas do Secretariado (Bíscoli \& Bilert, 2013). Por isso, há necessidade do comprometimento dos acadêmicos, profissionais e docentes com o pesquisar e tornar suas pesquisas referência para área secretarial. 
Contudo, evidencia-se que, apesar da inexistência de cursos de pós-graduação stricto sensu na área, é constante a preocupação dos docentes em aumentar sua titulação e, consequentemente, originar possibilidades de aprimorar a qualidade do ensino na graduação (Cielo et al., 2014).

Além disso, também existem poucos eventos científicos da área secretarial que promovem a discussão da evolução da pesquisa. No entanto, um dos eventos mais conhecidos da área é o Encontro Nacional Acadêmico de Secretariado Executivo- Enasec. O evento já teve três edições, mas a partir dos debates realizados no $2^{\circ}$ Enasec "foi possível perceber a necessidade e o amplo interesse de envolvimento dos pesquisadores na identificação e no desenvolvimento dos quesitos que possam levar à evolução da pesquisa em secretariado executivo" (Bíscoli, 2012, p. 41).

O Enasec atualmente é um evento da Associação Brasileira de Pesquisa em Secretariado (ABPSEC). Segundo o site da ABPSEC (2015), o evento acadêmico-científico visa discutir a pesquisa científica em secretariado em âmbito nacional, com a finalidade de desenvolver o meio acadêmico, científico e profissional e tem como público-alvo graduandos e pósgraduandos, docentes, pesquisadores das áreas e coordenadores de curso de todo o país.

Observa-se que o Enasec se torna cada vez mais reconhecido na área pelo espaço que abre para debater os diferentes temas que compõe o Secretariado Executivo. Pode-se perceber, também, que o número de trabalhos publicados oportuniza conhecer os diferentes pesquisadores da área e os diversos campos pesquisados no secretariado.

Por tal razão, o Enasec instigou o desenvolvimento desta pesquisa, pois se verifica que é uma oportunidade para publicação das diversas pesquisas dos profissionais e pesquisadores da área, como também um momento de troca experiências entre profissionais de diversas realidades do Brasil.

\section{METODOLOGIA}

Esta pesquisa caracteriza-se como um estudo bibliométrico, de natureza descritiva. A bibliometria refere-se a uma técnica quantitativa e estatística que visa medir os índices de produção e disseminação do conhecimento científico (Araújo, 2006). Paul Olet, em 1934, foi o primeiro pesquisador a aplicar o nome bibliometria à técnica para quantificar a ciência 
(Carrizo; Sainero, 2000). Nesse sentido, estudos bibliométricos são utilizados em áreas distintas do conhecimento para obter indicadores de produção científica (Ferreira, 2010).

Assim, para a construção das informações deste estudo, o modelo adotado como base foi o de trabalhos já publicados na área secretarial que utilizaram a bibliometria. Foi realizada uma busca no Portal de Periódicos da Capes e o resultado encontrado foi de um artigo científico: a produção de Silva; Barros e Barbosa (2012). Por isso, adotou-se esse estudo como embasamento para esta pesquisa.

A abordagem adotada foi a quantitativa devido ao fato de objetivar a realização da mensuração precisa de algo (Cooper \& Schindler, 2011). No caso de estudo, relaciona-se à quantificação das produções científicas, na área secretarial, no evento Enasec.

Quanto aos meios de investigação, a base de dados foram os anais da produção científica do evento, disponibilizados nos $C D-R O M$ e em arquivos digitais em formato .pdf. Para a consecução deste estudo tais produções foram ponderadas tendo como objetivo analisar bibliometricamente a produção científica das quatro edições do Enasec para identificar, então, as possibilidades de linha de pesquisa em Secretariado Executivo, com base nas produções científicas publicadas nos anais deste evento.

Para a coleta de dados realizou-se um levantamento dos trabalhos completos já publicados nas quatro edições do Enasec, compreendidas nos períodos de 2010, 2011, 2013 e 2015. O universo foi o acervo completo do Enasec, editado de maneira independente em quatro edições, perfazendo um total de 121 artigos. O material foi analisado entre maio e dezembro de 2015.

Dessa forma, na análise dos dados, os trabalhos completos foram categorizados por grupos de trabalho. Por fim, utilizou-se o pacote estatístico Statistical Package for the Social Sciences $\left(\right.$ SPSS $\left.{ }^{\circledR}\right)$ para tratamento dos dados e posterior suporte à análise descritiva.

$\mathrm{Na}$ sequência, os resultados encontrados por meio da análise bibliométrica são apresentados. Inicialmente houve a filtragem do número de publicações de trabalhos completos em cada edição do evento.

\section{ANÁLISE E DISCUSSÃO DOS RESULTADOS}

Na sequência, os resultados encontrados por meio da análise bibliométrica são apresentados. Inicialmente, procedeu a filtragem do número de publicações de trabalhos completos em cada edição do evento. 


\section{Quadro 1. Número de trabalhos completos por evento.}

\begin{tabular}{|c|c|}
\hline Evento & Total por evento \\
\hline I Enasec & 14 \\
\hline II Enasec & 40 \\
\hline III Enasec & 39 \\
\hline IV Enasec & 28 \\
\hline Total geral & $\mathbf{1 2 1}$ \\
\hline
\end{tabular}

Fonte: Elaborado pelas autoras (2015).

Ao realizar um comparativo entre as produções científicas dos quatro anos, observa-se um crescimento nas edições II e III em relação à primeira edição. E, apesar de apresentar uma redução no número de trabalhos completos na quarta edição, o evento apresenta, ainda, o dobro de trabalhos em 2015 quando comparados à edição de 2010.

A primeira edição do Enasec estabeleceu o objetivo de:

Reunir professores, acadêmicos, pesquisadores e coordenadores de curso para debates técnicocientíficos nos quais os focos eram a instituição de uma Linha de Pesquisa em Secretariado Executivo e a ampliação dos meios de divulgação importantes para a graduação em Secretariado Executivo, tais como Revistas Científicas e Anais de Eventos (1ºnasec, 2010).

Como o número relacionado aos anos de 2011 e 2013 são equitativos pode-se inferir que o menor número de trabalhos do primeiro evento pode relacionar-se ao fato de possível desconhecimento do evento por parte de alguns pesquisadores. Nesse sentido, espera-se que nas próximas edições o número de publicações eleve-se devido a maior divulgação do Enasec nas Universidades e, também, por meio do sítio eletrônico e nas redes sociais. E, dessa forma, desperte o interesse dos pesquisadores, tanto docentes quanto discentes, da área do secretarial com vistas a fortalecer a pesquisa e as problemáticas profissionais por meio de produções científicas atingindo, assim, uma maior gleba populacional. 


\section{Áreas de concentração das produções científicas do Enasec}

Para a análise das áreas de concentração das produções científicas do Enasec, utilizaram-se oito categorias, tendo como base os grupos de trabalhos definidos, pela ABPSEC, para o IV Enasec:

Quadro 2. Categorias das produções científicas do IV Enasec.

\begin{tabular}{|l|l|}
\hline \multicolumn{2}{|l|}{ Categoria } \\
\hline GT1 & Contexto da profissão e do mercado de trabalho \\
\hline GT2 & Assessoria e gestão secretarial \\
\hline GT3 & Consultoria e empreendedorismo em Secretariado \\
\hline GT4 & $\begin{array}{l}\text { Tecnologia, gestão da informação e comunicação } \\
\text { para o Secretariado }\end{array}$ \\
\hline GT5 & $\begin{array}{l}\text { Formação profissional, ensino e aprendizagem em } \\
\text { Secretariado }\end{array}$ \\
\hline GT6 & Pesquisa em Secretariado \\
\hline GT7 & Línguas (materna e estrangeiras) \\
\hline GT8 & Outros temas que interessam ao Secretariado \\
\hline
\end{tabular}

Fonte: Elaborado pelas autoras (2015).

\section{Áreas do I Enasec}

O próximo quadro apresenta o número de trabalhos completos publicados no I Enasec:

Quadro 3. Número de trabalhos completos I Enasec - 2010.

\begin{tabular}{|l|l|c|}
\hline & Categoria & $\begin{array}{c}\mathbf{N}^{\mathbf{d}} \text { trabalhos } \\
\text { completos }\end{array}$ \\
\hline GT1 & Contexto da profissão e do mercado de trabalho & 5 \\
\hline GT2 & Assessoria e gestão secretarial & 3 \\
\hline GT3 & Consultoria e empreendedorismo em Secretariado & 3 \\
\hline GT4 & Tecnologia, gestão da informação e comunicação para o Secretariado & 1 \\
\hline GT5 & Formação profissional, ensino e aprendizagem em Secretariado & 0 \\
\hline GT6 & Pesquisa em Secretariado & 1 \\
\hline GT7 & Línguas (materna e estrangeiras) & 0 \\
\hline GT8 & Outros temas que interessam ao Secretariado & $\mathbf{1 4}$ \\
\hline & Total & \\
\hline
\end{tabular}

Fonte: Elaborado pelas autoras (2015).

Revista de Gestão e Secretariado-GeSec, São Paulo, v. 7, n. 3, p 123-149, set./dez. 2016. 
No primeiro evento constata-se que a categoria que mais teve publicações foi a que trata do Contexto da profissão e do mercado de trabalho (GT1) totalizando 36\% dos trabalhos apresentados e, seguido pela categoria GT2 (Assessoria e gestão secretarial) e GT4 (Tecnologia, gestão da informação e comunicação para o Secretariado) totalizando 21,5\% cada. Ademais, duas categorias de pesquisa não foram contempladas com artigos: a área de pesquisa (GT6) e outros temas de interesse (GT8). Tal fator pode estar relacionado ao fato de que a pesquisa em secretariado está em fase de consolidação; por isso, há uma trajetória a ser percorrida com a finalidade de produzir avanços de conhecimentos científicos, consequentemente, solidificando a área em termos acadêmicos (Iizuka \& Almeida, 2014).

Gráfico 1. Número de trabalhos completos I Enasec - 2010.

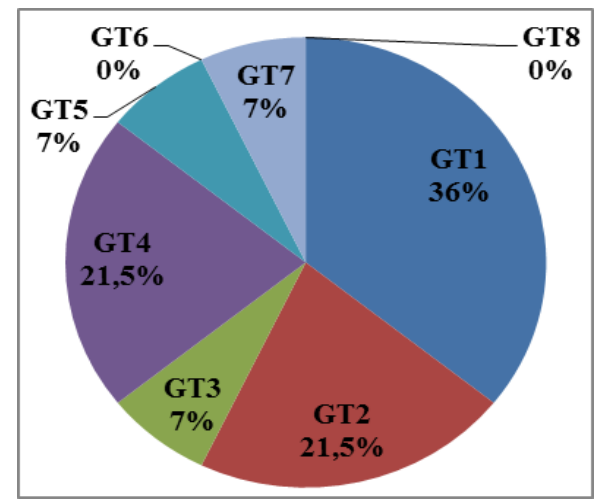

Fonte: Elaborado pelas autoras (2015).

Os dados apontam maior concentração de pesquisas nas áreas relacionadas ao mercado de trabalho e às áreas de assessoria. Visto que se faz necessário o desenvolvimento do campo teórico que alicerçará a prática das atividades secretariais, objetivando o entendimento do campo de atuação, é preciso estimular nos acadêmicos o interesse pela pesquisa científica (Françoso \& Jonas, 2011).

\section{Áreas do II Enasec}

A segunda edição do evento contou com 40 trabalhos completos. A evolução apresentada é de $185 \%$ quando comparados os números de publicações entre as duas edições. Para tanto, pode-se inferir que a linha proposta pelos organizadores do evento: “A evolução 
da profissão por meio da pesquisa" foi seguida, haja vista que as publicações contemplaram todas as categorias disponíveis.

Quadro 4. Número de trabalhos completos II Enasec - 2011.

\begin{tabular}{|l|l|c|}
\hline & Categoria & $\begin{array}{c}\mathbf{N}^{\mathbf{d e}} \text { trabalhos } \\
\text { completos }\end{array}$ \\
\hline GT1 & Contexto da profissão e do mercado de trabalho & 10 \\
\hline GT2 & Assessoria e gestão secretarial & 6 \\
\hline GT3 & Consultoria e empreendedorismo em Secretariado & 1 \\
\hline GT4 & Tecnologia, gestão da informação e comunicação para o Secretariado & 4 \\
\hline GT5 & Formação profissional, ensino e aprendizagem em Secretariado & 4 \\
\hline GT6 & Pesquisa em Secretariado & 4 \\
\hline GT7 & Línguas (materna e estrangeiras) & 6 \\
\hline GT8 & Outros temas que interessam ao Secretariado & $\mathbf{4 0}$ \\
\hline & Total & 4 \\
\hline
\end{tabular}

Fonte: Elaborado pelas autoras (2015).

Observa-se que a categoria GT1 que trata das experiências práticas do secretário obteve o maior número de publicações, nesta edição do evento, atingindo $25 \%$ do total de trabalhos completos.

O número de publicações por grupo de trabalho, na segunda edição, pode ser melhor visualizado no Gráfico 2.

Gráfico 2. Número de trabalhos completos II Enasec - 2011.

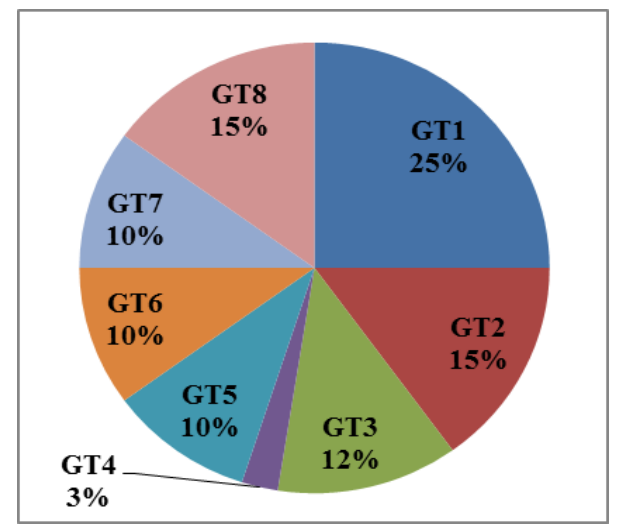

Fonte: elaborado pelas autoras (abr., 2015).

Revista de Gestão e Secretariado-GeSec, São Paulo, v. 7, n. 3, p 123-149, set./dez. 2016. 
Ademais, a categoria que envolve o contexto da profissão e do mercado de trabalho destacou-se, também, na primeira e quarta edições com maior número de publicações por GT. A concentração de pesquisas nessa área pode ser o reflexo das modificações do perfil dos secretários executivos, geradas pela globalização, e devido ao crescimento e reconhecimento da profissão, assim as Instituições de Ensino Superior preocupam-se em qualificar os alunos em harmonia com as tendências do mercado (Reis, 2011). Portanto, pode-se dizer que as pesquisas demonstram a preocupação em destacar o secretariado como profissão presente no mercado atual.

\section{Áreas do III Enasec}

Em 2011 estabeleceu-se que, a partir da referida edição, o Enasec seria bienal. Dessa maneira, a terceira edição do evento ocorreu em 2013. Nesse encontro, com número de trabalhos completos igual a 39; o tema proposto pela organização foi "O conhecimento científico e as novas tecnologias em Secretariado: relevância e impacto social”.

Quadro 5. Número de trabalhos completos III Enasec - 2013.

\begin{tabular}{|l|l|c|}
\hline & Categoria & $\begin{array}{c}\mathbf{N}^{\mathbf{d}} \text { de trabalhos } \\
\text { completos }\end{array}$ \\
\hline GT1 & Contexto da profissão e do mercado de trabalho & 0 \\
\hline GT2 & Assessoria e gestão secretarial & 6 \\
\hline GT3 & Consultoria e empreendedorismo em Secretariado & 4 \\
\hline GT4 & Tecnologia, gestão da informação e comunicação para o Secretariado & 2 \\
\hline GT5 & Formação profissional, ensino e aprendizagem em Secretariado & 10 \\
\hline GT6 & Pesquisa em Secretariado & 4 \\
\hline GT7 & Línguas (materna e estrangeiras) & 4 \\
\hline GT8 & Outros temas que interessam ao Secretariado & $\mathbf{3 9}$ \\
\hline & Total & 4 \\
\hline
\end{tabular}

Fonte: Elaborado pelas autoras (2015).

As categorias GT5 (Formação profissional, ensino e aprendizagem em Secretariado) e GT6 (Pesquisa em Secretariado) apresentaram um aumento considerável nas publicações na edição de 2013 quando comparada às edições anteriores. Por isso, evidencia-se que os pesquisadores se mostram mais conscientes em relação à abrangência da área de formação 
docente e seus meios de aprendizagem e, também, na área relacionada à discussão da pesquisa secretarial para que, então, se torne uma subárea do conhecimento.

Assim, evidencia-se que é fundamental a complementação do conhecimento originado pelas pesquisas científicas, haja vista que são os componentes intelectuais necessários à construção tanto do mundo profissional quanto acadêmico (Françoso \& Jonas, 2011).

Com 16\%, o GT2 (Assessoria e gestão secretarial), destacou-se dos grupos GT3 (Consultoria e empreendedorismo em Secretariado), GT7 (Línguas materna e estrangeiras) e GT8 (Outros temas que interessam ao Secretariado) que obtiveram 10\% de publicações.

Diferente dos anos anteriores, a categoria GT1 (Contexto da profissão e do mercado de trabalho) neste ano não obteve nenhum artigo publicado (0\%), sendo mais um indicador de mudança nas linhas de pesquisa dos integrantes do curso. Outra categoria que apresentou uma redução no número de publicações foi o GT4 (Tecnologia, gestão da informação e comunicação para o Secretariado).

Gráfico 3. Número de trabalhos completos III Enasec - 2013.

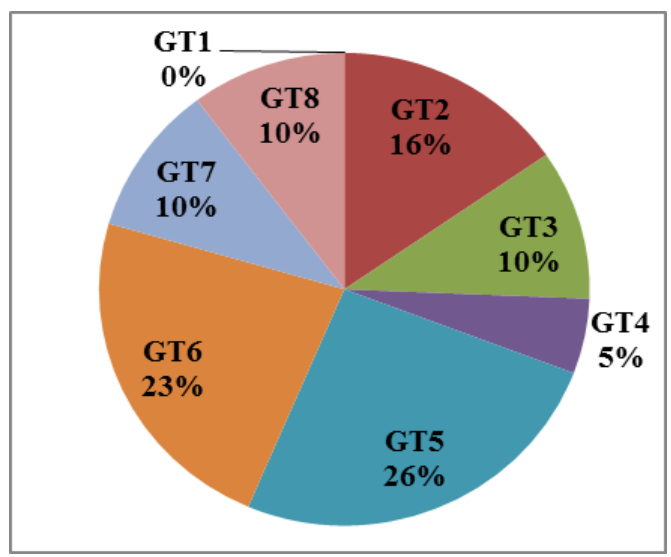

Fonte: elaborado pelas autoras (abr., 2015).

Áreas do IV Enasec

O quadro seguinte apresenta o número de publicações por área em relação ao quarto evento, realizado em 2015 que totalizou 28 artigos completos. O tema proposto nesse ano foi: "Pesquisa Secretarial: construção de conhecimento e sociedade" (IV Enasec, 2015). 
Quadro 6. Número de trabalhos completos IV Enasec - 2015.

\begin{tabular}{|l|l|c|}
\hline & Categoria & $\begin{array}{c}\mathbf{N}^{\mathbf{d}} \text { de trabalhos } \\
\text { completos }\end{array}$ \\
\hline GT1 & Contexto da profissão e do mercado de trabalho & 7 \\
\hline GT2 & Assessoria e gestão secretarial & 2 \\
\hline GT3 & Consultoria e empreendedorismo em Secretariado & 1 \\
\hline GT4 & Tecnologia, gestão da informação e comunicação para o Secretariado & 6 \\
\hline GT5 & Formação profissional, ensino e aprendizagem em Secretariado & 7 \\
\hline GT6 & Pesquisa em Secretariado & 2 \\
\hline GT7 & Línguas (materna e estrangeiras) & 2 \\
\hline GT8 & Outros temas que interessam ao Secretariado & $\mathbf{2 8}$ \\
\hline & Total & 1 \\
\hline
\end{tabular}

Fonte: Elaborado pelas autoras (2015).

No último evento constata-se que todas as categorias foram contempladas com artigos completos, destacando-se os grupos Contexto da profissão e do mercado de trabalho (GT1) e Pesquisa em Secretariado (GT6), ambos com de 25\% dos artigos. Comparando com o III Enasec, constata-se que a GT1 (Contexto da profissão) obteve novamente atenção dos pesquisadores, conforme análises anteriores das edições I e II.

Essa tendência está relacionada ao momento econômico do país, que necessita de profissionais de secretariado com "[..] características e capacidade intelectual suficiente para acompanhar as tendências da economia, atuando de forma assertiva ao lado do executivo". (Santos \& Moretto, 2011).

Outro grupo que mereceu destaque foi o de Formação profissional, ensino e aprendizagem em Secretariado (GT5), com $21 \%$ das publicações, ficando claro o comprometimento da formação profissional com a docência e as áreas de pesquisa. 


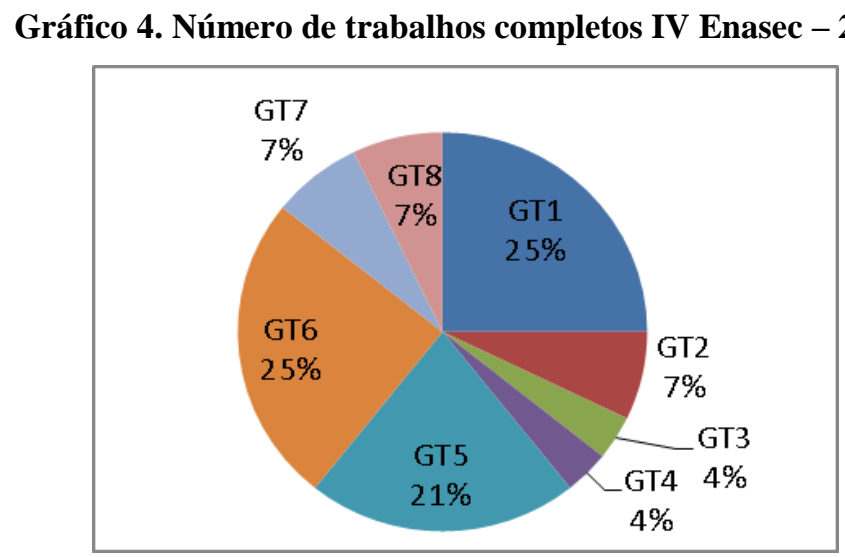

Fonte: elaborado pelos autores (2015)

Em relação às outras categorias, a que mais apresentou queda foi GT2 (Assessoria e gestão secretarial) em comparação com o III Enasec, representando apenas 7\% das publicações. Sobre as categorias GT3 (Consultoria e empreendedorismo) e GT4 (Tecnologia, gestão da informação e comunicação para o Secretariado), ambas ficaram com 4\%, número menor que no evento anterior. Já sobre as Línguas (maternas e estrangeiras) - GT7 e GT8 (Outros temas), a redução na produção foi de $50 \%$.

Após as análises das edições do evento, verifica-se que o constante crescimento no número de publicações e a participação em todos os grupos de pesquisa, evidencia o envolvimento das instituições de ensino para com a pesquisa na área secretarial. Fica evidente que as pesquisas estão seguindo para o melhor entendimento do contexto da profissão e, seus aspectos e benefícios para o mercado de trabalho. E por fim, verifica-se o crescimento na área de pesquisa e formação docente, um perfil novo dos profissionais em secretariado; tal fator pode ser observado por meio do título do IV Enasec direcionado à construção do conhecimento e sociedade.

Neste estudo, adota-se GT como sinônimo a linhas de pesquisa. Por meio das análises realizadas, constatou-se que, devido ao pequeno número de GTs e publicações, ainda não se tornou possível inferir sobre as linhas de pesquisa. Nesse sentido, a pesquisa científica em Secretariado Executivo tem se evidenciado no processo da construção da identidade secretarial (Maçaneiro, 2012). 


\section{Termos relacionados à área secretarial mais utilizados nas produções científicas e reincidência dos autores mais citados}

Para realização do levantamento das referências utilizadas nas produções científicas optou-se pela observação e análise do título da referência citada. Para tanto, foram consideradas somente as referências que possuíam em seu título termos relacionados à área secretarial. O quadro 7 apresenta o número de aparições dos termos considerados.

Quadro 7. Número de ocorrências dos termos relacionados à área secretarial.

\begin{tabular}{|c|c|}
\hline Palavras-chave & $\begin{array}{l}\mathrm{N}^{\mathbf{r}} \text { de } \\
\text { aparições }\end{array}$ \\
\hline Atividades secretariais & 3 \\
\hline Competências secretariais & 4 \\
\hline Eventos/cerimonial/protocolo & 23 \\
\hline Gestão do conhecimento secretarial & 2 \\
\hline Gestão secretarial; gestor secretarial & 46 \\
\hline Práticas secretariais & 1 \\
\hline Profissão secretarial & 14 \\
\hline Secretária (o); Secretária (o) Executiva (o) & 215 \\
\hline Secretariado; Secretariado Executivo & 498 \\
\hline Supersecretária & 2 \\
\hline Total & 809 \\
\hline
\end{tabular}

Fonte: Elaborado pelas autoras (2015).

Por meio das palavras-chave analisadas observa-se que os termos Secretariado; Secretariado Executivo; Secretária (o) e Secretária (o) Executiva (o) foram os que apresentam maior número de ocorrências. Nota-se que a reincidência dessas palavras encontradas nos títulos coincide com a evolução dos trabalhos aprovados em que se destacaram os grupos de trabalho relacionados ao contexto da profissão e do mercado de trabalho; formação profissional, ensino e aprendizagem em Secretariado e pesquisa em secretariado.

Nesse sentido, pode-se dizer que existe, por parte dos pesquisadores, uma inquietação quanto à modernização das temáticas que norteiam o secretariado. Para atender a demanda de pesquisas aplicadas ao secretariado, os cursos superiores objetivam responder às questões que 
emergem na profissão, como também buscam avançar os estudos científicos com a finalidade de atribuir identidade ao curso de Secretariado Executivo (Cordeiro \& Fávero, 2011).

Após essa filtragem, realizou-se a identificação da reincidência dos autores mais citados nos trabalhos completos publicados nas quatro edições do Enasec. Para classificação, a escala com valor de 8 foi utilizada, ou seja, somente autores que foram citados mais de 8 vezes, totalizando uma frequência superior a $1 \%$, com base nos dados analisados, é que foram considerados. O número total de autores que foram identificados, por meio da bibliometria, é igual a 20 autores (Quadro 8).

Quadro 8. Número de ocorrências dos autores mais citados nos trabalhos completos publicados nas quatro edições do Enasec.

\begin{tabular}{|l|c|}
\hline Autor(a) & $\mathbf{N}^{\mathbf{0}}$ de aparições \\
\hline DURANTE, Daniela Giareta & 41 \\
NONATO JUNIOR, Raimundo & 39 \\
BÍSCOLI, Fabiana Regina Veloso & 29 \\
SABINO, Rosimeri Ferraz & 29 \\
MEDEIROS, João Bosco & 21 \\
HERNANDES, Sonia & 20 \\
D'ELIA, Maria Elizabete Silva & 19 \\
NEIVA, Edméa Garcia & 17 \\
CIELO, Ivanete Daga & 16 \\
MARCHELLI, Paulo Sérgio & 13 \\
ROCHA, Fabio Gomes & 13 \\
SANTOS, Maria Elisabete Mariano dos & 13 \\
SCHMIDT, Carla Maria & 12 \\
BORTOLOTTO, Márcia Fernanda Pasa & 12 \\
PORTELA, Keyla Christina Almeida & 12 \\
SCHUMACHER, Alexandre José & 12 \\
HOELLER, Patricia Agostinho Freitas & 10 \\
NATALENSE, Maria Liana de Castro & 10 \\
SANCHES, Fernanda & 10 \\
MAÇANEIRO, Marlete Beatriz & 9 \\
\hline
\end{tabular}

Fonte: Elaborado pelas autoras (2015). 
A pesquisa identificou o maior número de ocorrências da autora Daniela Giareta Durante seguida de Raimundo Nonato Júnior e de Fabiana Regina Veloso Bíscoli. O Gráfico 5 apresenta uma melhor visualização do número de ocorrências de cada autor, com reincidência maior que 8 :

Gráfico 5. Número de ocorrências de cada autor com reincidência maior que 8.

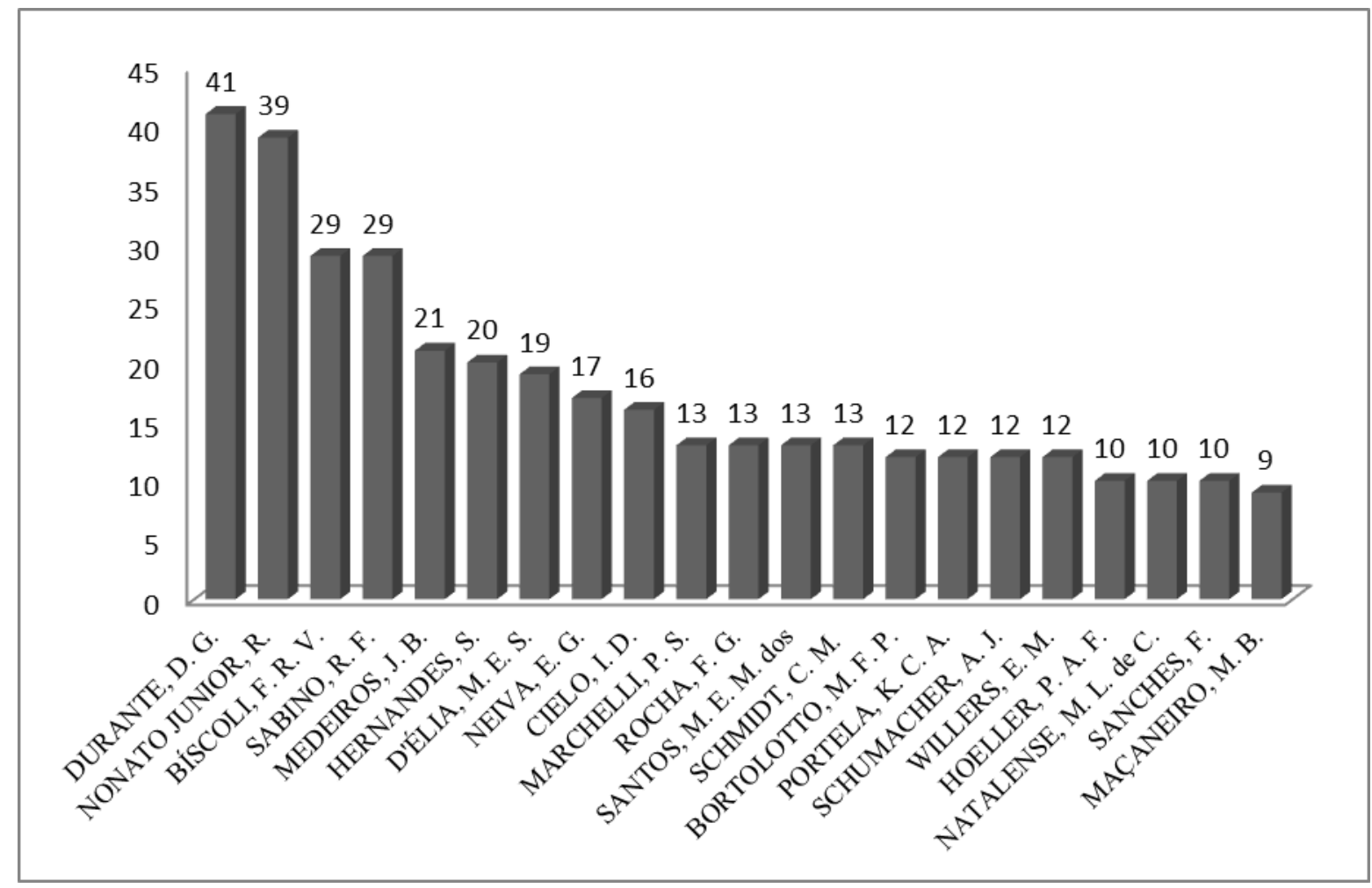

Fonte: Elaborado pelas autoras (2015).

Pode-se inferir que os autores evidenciados nas edições do evento abordam discussões que romperam paradigmas na área secretarial e, consequentemente, trouxe avanços significativos para a profissão. Observa-se a partir do levantamento da formação dos autores que todos, de alguma maneira, podem contribuir para a área secretarial, pois, pode ser visualizada como um fator positivo por demandar pesquisas na área que fortaleçam a identidade profissional (Maçaneiro, 2012).

\section{Reincidências de publicações por instituição nas produções científicas}

O quarto objetivo específico visou a identificação das reincidências de publicações por Instituição nas produções científicas (Quadro 9). Ressalta-se que na verificação da frequência de publicações, por instituição, considerou-se somente a instituição a que o primeiro autor 
pertence no caso de publicações em conjunto. E levou em consideração que os autores estão enquadrados como discentes ou docentes das instituições relacionadas.

Quadro 9. Total de trabalhos completos publicados, por instituição, nas quatro edições do Enasec.

\begin{tabular}{|c|c|}
\hline Instituição & Quantidade \\
\hline Embrapa Clima Temperado & 1 \\
\hline Faculdade Alvorada & 2 \\
\hline Faculdade Bagozzi - Grupo Educacional & 1 \\
\hline Faculdade de Pinhais - Fapi & 1 \\
\hline Faculdade Internacional de Curitiba - Facinter & 1 \\
\hline Faculdades Integradas do Brasil - Unibrasil & 2 \\
\hline Faculdades Integradas do Brasil - Uninter & 2 \\
\hline Universidade de Passo Fundo - UPF & 10 \\
\hline Universidade de Santa Cruz do Sul - Unisc & 2 \\
\hline Universidade do Estado do Pará - Uepa & 2 \\
\hline Universidade do Extremo Sul Catarinense - Unesc & 1 \\
\hline Universidade do Oeste de Santa Caratina - Unoesc & 2 \\
\hline Universidade Estadual de Londrina - Uel & 9 \\
\hline Universidade Estadual de Maringá - Uem & 7 \\
\hline Universidade Estadual do Centro Oeste - Unicentro & 5 \\
\hline Universidade Estadual do Oeste do Paraná - Unioeste & 27 \\
\hline Universidade Estadual Paulista - Unesp & 1 \\
\hline Universidade Federal da Paraíba - UFPB & 18 \\
\hline Universidade Federal de Santa Catarina - UFSC & 6 \\
\hline Universidade Federal de Viçosa - UFV & 2 \\
\hline Universidade Federal do Amapá - Unifap & 1 \\
\hline Universidade Federal do Ceará - UFC & 7 \\
\hline Universidade Federal do Pará - UFPA & 1 \\
\hline Universidade Federal do Paraná - UFPR & 2 \\
\hline Universidade Luterana do Brasil - Ulbra & 1 \\
\hline Universidade Nove de Julho - Uninove & 4 \\
\hline Universidade Pernambuco - Upe & 1 \\
\hline Universidade Regional do Noroeste do Estado do Rio Grande do Sul - Unijuí & 1 \\
\hline Universidade Tecnológica Federal do Paraná - UTFPR & 1 \\
\hline Total & 121 \\
\hline
\end{tabular}

Fonte: Elaborado pelas autoras (2015)

Revista de Gestão e Secretariado-GeSec, São Paulo, v. 7, n. 3, p 123-149, set./dez. 2016. 
Observa-se que a Universidade Estadual do Oeste do Paraná - Unioeste é a instituição que possui o número mais elevado de produções no Enasec totalizando 27 trabalhos completos. Na sequência, encontra-se a Universidade Federal da Paraíba - UFPB com 18 produções e em terceiro lugar a Universidade de Passo Fundo obteve 10 publicações. Para melhor visualização da classificação, o total de publicações foi disposto no Gráfico 6:

Gráfico 6 . Total de trabalhos completos publicados, por instituição, nas quatro edições do Enasec.

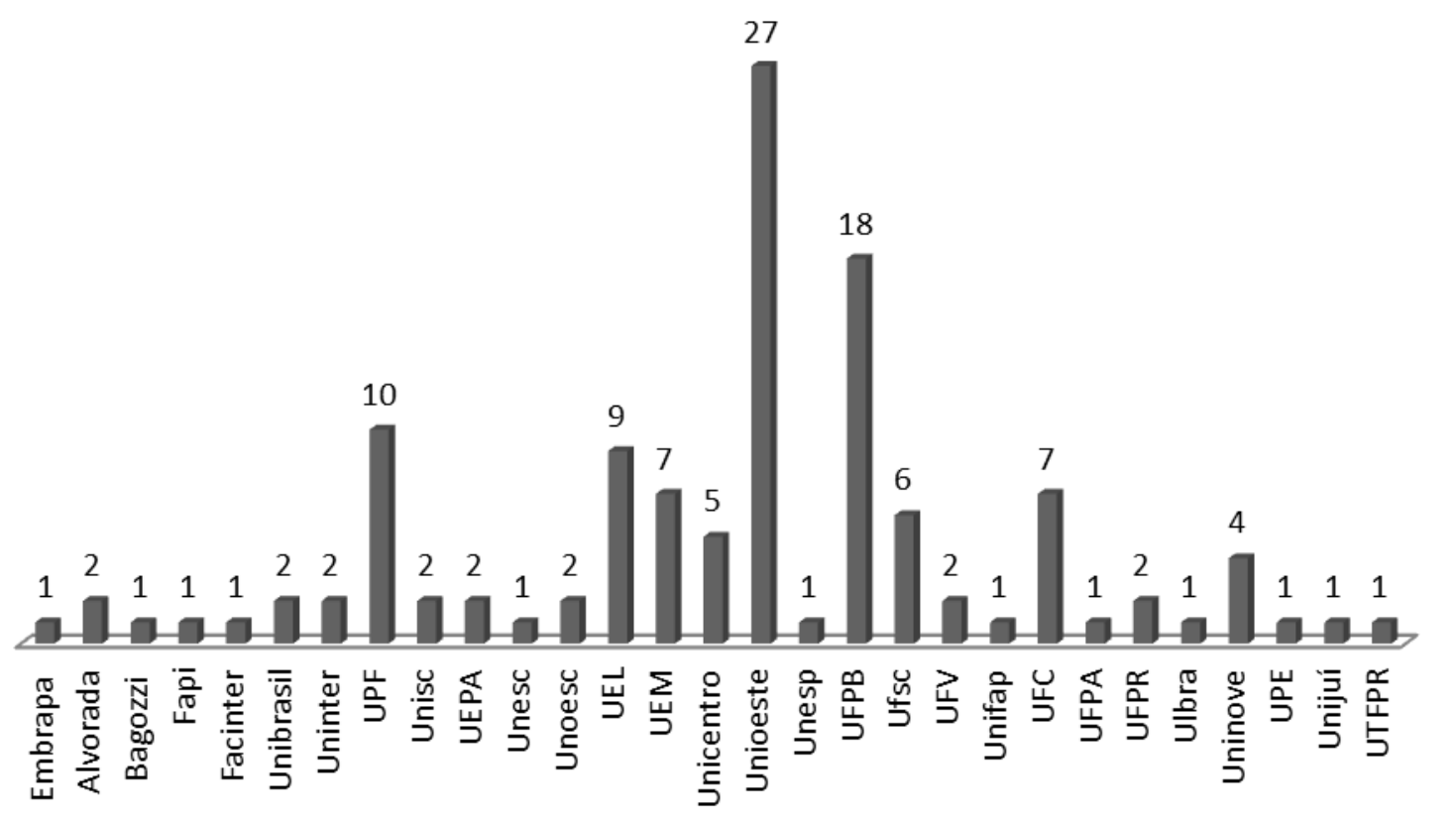

Fonte: Elaborado pelas autoras (2015).

Verifica-se que as três instituições que mais publicaram foram, coincidentemente, as três instituições sedes dos eventos já ocorridos; fato este que demonstra uma forte regionalização das publicações segundo as sedes dos eventos. Contudo, observou-se que a Universidade Estadual de Londrina, sede do IV Enasec não publicou significativamente no evento de 2015. Tal afirmativa corrobora que a dimensão nacional do evento ainda está em construção.

Nessa perspectiva, a pesquisa científica em secretariado encontra-se em fase inicial, portanto, existe um percurso a ser transcorrido a fim de solidificar a área e conquistar avanços de conhecimentos científicos (Iizuka \& Almeida, 2014). Nesse sentido, ressalta-se que o secretariado não pode basear-se somente na aplicação prática, pois, é indispensável a complementação do conhecimento gerado pelas pesquisas científicas como elementos 
intelectuais necessários à construção do mundo profissional e acadêmico (Françoso \& Jonas, 2011).

\section{CONSIDERAÇÕES FINAIS}

Este artigo teve como objetivo geral analisar bibliometricamente a produção científica dos autores nos anais do Enasec, categorizando-as por grupos de trabalho.

Os grupos de trabalho que obtiveram mais publicações foram o GT1 (Contexto da profissão e do mercado de trabalho); GT5 (Formação profissional, ensino e aprendizagem em Secretariado) e GT6 (Pesquisa em Secretariado). Os três grupos de trabalho apresentaram 22, 21 e 20 trabalhos completos, respectivamente, quando se considerando o somatório das quatro edições do evento. Uma das razões para o destaque desses grupos pode estar relacionada ao fato de serem temas atuais e de grande preocupação dos profissionais da área.

Dentre os autores mais citados, evidenciam-se Daniela Giareta Durante, Raimundo Nonato Júnior e Fabiana Regina Veloso Bíscoli, respectivamente. Dentre as instituições que mais publicaram destacam-se a Unioeste, a UFPB e a UPF. Observa-se que as universidades que mais publicaram foram às instituições sedes dos eventos ocorridos; fato este que demonstra grande regionalização das publicações, devido à facilidade no acesso.

Dessa forma, pode-se inferir que o evento já alcançou dimensões significativas e tem desempenhado um papel importante por servir como fonte de pesquisa entre os pesquisadores e profissionais da área, sendo mais um instrumento de divulgação das linhas de pesquisa no Secretariado Executivo.

Este estudo possibilitou maior compreensão sobre a necessidade do desenvolvimento de pesquisas científicas na área secretarial, evidenciando a relevância de se conhecer os fatores a serem aperfeiçoados. Ressalta-se que a finalidade deste estudo foi a de analisar a produção científica sem a pretensão de somente mensurar resultados obtidos e, sim, de apresentar uma breve reflexão sobre o desenvolvimento da pesquisa científica em secretariado.

Os resultados obtidos por meio deste estudo evidenciam o potencial da área secretarial na pesquisa científica. Um exemplo que pode ser citado é o aumento considerável de produções na segunda e terceira edições do Enasec quando comparados à primeira edição. Todavia, ressalta-se que para que as linhas de pesquisa em secretariado possam expandir-se é necessário superar alguns obstáculos por meio da realização de pesquisas que consolidem a área secretarial como, por exemplo, o reconhecimento de linhas de pesquisa pela Capes. 
No tocante às possibilidades de linha de pesquisa em Secretariado Executivo, com base nas produções científicas publicadas nos anais do Enasec nas quatro edições do evento, verifica-se que não é possível inferir sobre as linhas de pesquisas devido ao pequeno número de GTs e publicações existentes no evento.

Como proposta para pesquisas futuras sugere-se que sejam analisadas não somente as publicações científicas do Enasec mas, também, as publicações das revistas científicas da área para que se possa, efetivamente, identificar as linhas de pesquisa em secretariado.

Por tratar-se de uma pesquisa aplicada a uma amostra determinada, em específicos trabalhos completos publicados no evento Enasec, os resultados deste estudo não podem ser generalizados, visto que, cada evento possui uma abordagem diferente e os outros tipos de eventos são conceituados no seu âmbito.

\section{REFERÊNCIAS}

Araújo, C. A. A. (2006). Bibliometria: evolução histórica e questões atuais. Em Questão. Porto Alegre, 12 (1), 11-32.

Arruda, A. S. (2013). A pesquisa científica como ferramenta de (re)construção do Secretariado Executivo. Anais do $3^{\circ}$ Encontro Nacional Acadêmico de Secretariado Executivo. João Pessoa.

Associação Brasileira de Pesquisa em Secretariado (2010). ABPSEC Recuperado em 25 de junho, 2015, de http://www.abpsec.com.br/abpsec/index.php/i-enasec-apresentacao.

Bíscoli, F. R. V. (2012). A evolução do Secretariado Executivo: caminhos prováveis a partir dos avanços da pesquisa científica e dos embates teóricos e conceituais na área. In: Durante, D. G (org). (2012). Pesquisa em Secretariado: cenários, perspectivas e desafios. Passo Fundo: Ed. Universidade de Passo Fundo.

Bíscoli, F. R. V; \& Cielo, I. D. (2004). Gestão organizacional e papel do secretário executivo. Revista Expectativa. Toledo: Edunioeste, 3,(3). 11-19.

Bíscoli, F. R. V. \& Bilert, V. S. S. (2013). A evolução do Secretariado Executivo: caminhos prováveis a partir dos avanços da pesquisa científica e dos embates teóricos e conceituais na área. Revista Expectativa, 12(12).

Carrizo Sainero, G. (2000). Hacia un concepto de biblimetria. Revista de Investigación Iberoamericana em Ciencia de la Información y Documnetación, 1(2).

Cielo, I. D.; Schmidt, C. \& Wenningkamp, K. R. (2014). Secretariado executivo no Brasil: quo vadis? Revista de Gestão e Secretariado - GeSec, 5(3), 49-70. 
Cooper, D. R. \& Schindler, P. S. (2011). Métodos de pesquisa em administração. Porto Alegre: Bookman.

Cordeiro, R. L. \& Fávero, A. A. (2011). A pesquisa no Secretariado Executivo da UPF: limites e avanços. Anais do $2^{\circ}$ Encontro Nacional Acadêmico de Secretariado Executivo. Passo Fundo.

Durante, D. G. (2012). A evolução da profissão secretarial por meio da pesquisa. In: Durante, D. G (org). (2012). Pesquisa em secretariado: cenários, perspectivas e desafios. Passo Fundo: Ed. Universidade de Passo Fundo.

Durante, D. G.; Vaz, C. F. M.; Bertoletti, R.; Santos, M. E. M. \& Chais, C. (2011). A atuação e ascensão profissional a partir da formação em Secretariado Executivo: levantamento com egressos da UPF. Anais do $2^{\circ}$ Encontro Nacional Acadêmico de Secretariado Executivo. Passo Fundo.

Enasec. I Encontro Nacional Acadêmico de Secretariado Executivo, I, 2010, Toledo. Universidade Estadual do Oeste do Paraná, 2010. Recuperado em 25 de junho, 2015 de http://<http://www.abpsec.com.br/abpsec/index.php/i-enasec-apresentacao>.

Enasec. IV Encontro Nacional Acadêmico de Secretariado Executivo, IV, 2015, Londrina. Pesquisa Secretarial: construção de conhecimento e sociedade. Universidade Estadual de Londrina, 2015. Recuperado em 25 de junho, 2015 de http://<www.abpsec.com.br/abpsec/index.php/eventos/enasec>.

Fávero, A. A. (2012). "Decifra-me ou te devoro": pesquisa na sociedade do conhecimento. In: Durante, D. G (org). (2012). Pesquisa em Secretariado: cenários, perspectivas e desafios. Passo Fundo: Ed. Universidade de Passo Fundo.

Ferreira, A. G. C. (2010). Bibliometria na avaliação de periódicos científicos. DataGramaZero - Revista de Ciência da Informação, 11(3).

Françoso, A. C.\& Jonas, R. A. P. (2011). O profissional docente formado em Secretariado Executivo: a importância de sua atuação na graduação. Anais do $2^{\circ}$ Encontro Nacional Acadêmico de Secretariado Executivo. Passo Fundo.

Iizuka, E. S.\& Almeida, W. A. G. (2014). Produção acadêmica em Secretariado: análise dos artigos da Revista de Gestão e Secretariado - GeSec e da Revista Secretariado Executivo em Revist@ entre 2005 e 2012. Revista de Gestão e Secretariado-GeSec, 5(3), 71-93.

Maçaneiro, M. B. (2012). A construção da identidade científica em Secretariado Executivo. In: Durante, D. G (org). (2012). Pesquisa em secretariado: cenários, perspectivas e desafios. Passo Fundo: Ed. Universidade de Passo Fundo.

Nonato Júnior, R. (2009). Epistemologia e teoria do conhecimento em Secretariado Executivo: Fundação das Ciências da Assessoria. Fortaleza: Expressão Gráfica. 
Reis, A. K. G. (2011). Fatores de atratividade do curso de Secretariado Executivo Trilíngue da Universidade Federal de Viçosa. Anais do $2^{o}$ Encontro Nacional Acadêmico de Secretariado Executivo. Passo Fundo.

Santos, M. E. \& Moretto, C. F. (2011). O mercado de trabalho do secretário executivo no contexto da dinâmica produtiva e do emprego recentes no Brasil. Secretariado Executivo em Revist@, 7.

Silva, J. S. da; Barros, C. de M. P.\& Barbosa, M. F. S. (2012). Fundamentação da gestão secretarial: um estudo bibliométrico. Revista de Gestão e Secretariado - GeSec, 3(2), 106126. 